\title{
"y sobre las armas se concertaron las paces": explorando las rutinas de los acuerdos diplomáticos coloniales
}

Aceptación: Diciembre - 2007

Aprobación: Mayo - 2008

Lidia R. Nacuzzi y Carina P. Lucaioli*

\section{RESUMEN}

En este artículo proponemos un análisis comparativo de las negociaciones y tratados de paz acordados entre los grupos indígenas y los funcionarios coloniales en el Chaco y la Pampa durante el siglo XVIII. Consideraremos cómo fueron construidos los "pedidos de paz", en qué contextos y coyunturas regionales tuvieron lugar y buscaremos identificar los intereses implícitos de cada una de las partes y las distintas estrategias de interacción -intercambios de objetos, fundación de reducciones, liberación de cautivos- en el acto de establecer los acuerdos entre hispanocriollos e indígenas, en estos espacios de frontera en donde el control de la Corona no era efectivo y los grupos indígenas conservaban su independencia.

PALABRAS CLAVE: pedidos de paz, estrategias interétnicas, siglo XVIII, Pampa, Chaco

\section{ABSTRACT}

In this article we propose a comparative analysis of the negotiations and peace treaties between the indigenous groups and the colonial authorities in the Chaco and the Pampa, during the 18th century. We will consider how these agreements were constructed, the contexts and regional conjunctures they took place and we will think about how to identify the implicit interests and the different strategies of interaction -exchanges of objects, foundation of reductions, liberation of captives- at once of establishing the agreements between hispanocriollos and natives, in these borders where the control of the crown was not effective and the indigenous groups they were preserving his autonomy.

KEY WORDS: peace treaties, interethnic strategies, 18th century, Pampa, Chaco

* Sección Etnohistoria del Instituto de Ciencias Antropológicas, Universidad de Buenos Aires / CONICET. 


\section{Introducción}

En este artículo proponemos un enfoque comparativo para el análisis de los acuerdos de paz pactados entre los grupos indígenas y los sectores coloniales durante el siglo XVIII, en dos espacios de frontera que venimos estudiando desde distintas perspectivas (Nacuzzi, Lucaioli y Nesis 2008): la región sur del Chaco y la Pampa y norte de la Patagonia. Ya entrado el siglo XVIII, ambas regiones continuaban fuera del dominio efectivo de la Corona española y, dada su condición de nómades, sus agrupaciones indígenas mantenían una notable autonomía política y económica. Sin embargo, el contacto de estos grupos con los pobladores coloniales delineó múltiples relaciones interétnicas, tanto pacíficas como violentas: intercambios de bienes, circulación de informaciones, pedidos de ayuda, alianzas más o menos formales y rupturas que daban lugar a malones - del lado indígena- o a incursiones punitivas del lado español. En este marco se establecieron los primeros acuerdos de paz.

En trabajos anteriores nos hemos ocupado de los acuerdos verbales como uno de los ejes de los intercambios entre indígenas y españoles en el espacio de la reducción de San Jerónimo fundada en 1749 (Lucaioli 2006) y de una comparación del texto de ciertos acuerdos con los mocovíes y otros documentados para la región pampeana en 1742 y en la década de 1770 (Nacuzzi 2006)' 1 .

Aquí nos proponemos retomar esta discusión, profundizando los ejes de reflexión que se apartan de lo meramente escrito en el acuerdo e incorporando al análisis otros documentos como: instrucciones previas, cartas, borradores, tratados posteriores, actas de fundación, relatos de otros actores. Remarcamos que, apartándonos del texto de los tratados, consideraremos cómo fueron construidos los "pedidos de paz", tanto desde el lado indígena como desde el español, en qué contextos y coyunturas regionales tuvieron lugar y buscaremos identificar los distintos intereses implícitos en el acto de establecer cada tratado de paz. Para ello, también vamos a analizar algunos acuerdos que no tuvieron una expresión escrita y de los cuales no se conocen los artículos o capítulos definidos en su negociación.

Muchos documentos producidos entre 1740 y 1770 relatan el encuentro y diálogo entre caciques indígenas y funcionarios coloniales, haciendo referencia al establecimiento de pactos o relaciones de amistad. En estos relatos, la formalidad de un acuerdo de paz muchas veces quedaba reducida a su sola mención, sin registro explícito de los ítemes pactados, en caso de que hubieran existido. Sin embargo, contienen valiosa información de esos encuentros que permiten entrever $y$ reconstruir el entramado de derechos y obligaciones contraídos por ambas partes.

\section{Los espacios de la paz}

La ocupación colonial presentó diferencias en las regiones chaqueña y pampeanopatagónica. El Chaco no colonizado constituía un espacio poco conocido aunque codiciado, ya que se buscaba establecer rutas que permitieran una comunicación más directa entre las ciudades establecidas en sus márgenes: Santa Fe, Corrientes, Asunción, Tucumán, Santiago del Estero y Córdoba. Los intentos desde alguno de estos frentes por desplazar a los grupos indígenas que acosaban su territorio, provocaban inmediatamente conflictos en las jurisdicciones de otras ciudades. La frontera sur quedó establecida en el río Salado desde mediados del siglo XVII (Bechis 2008), a pocos kilómetros de Buenos Aires, siendo este curso de agua la línea que marcaba el inicio de una extensísima región de límites desconocidos y lejanos donde la estrategia de mantener a los grupos indígenas más allá de la frontera resultó ser el recurso más viable y económico por más de dos siglos.

1 Diferentes especialistas se han ocupado de los tratados de paz con las pueblos indígenas. La recopilación de Levaggi (2000) nos dio un acabado panorama de la cantidad de acuerdos diplomáticos que existieron en el territorio argentino. Otros autores han enfocado el tema desde el punto de vista comparativo (Lázaro Ávila 1998, 1999 y 2002), como estrategias de indios y blancos manejando períodos de guerra y de paz para obtener bienes y otros beneficios (Crivelli Montero 1991, Bechis 2008), como mecanismos de perturbación en las sociedades indígenas (Tamagnini y Pérez Zavala 2002), confrontando lo que se acuerda verbalmente con lo que queda expresado por escrito (Roulet 2004), como instrumentos de relaciones asimétricas (Briones y Carrasco 2000), como estrategias políticas desplegadas por los mocovíes en el marco de las paces establecidas en la década de 1770 (Nesis 2007). 
A pesar de estas diferencias, en ambos espacios se implementaron políticas de colonización orientadas tanto a relocalizar a los grupos en reducciones -mediante acuerdos o por la fuerza- como a erradicarlos por medio de expediciones punitivas. Desde inicios de la Colonia, los proyectos fronterizos llevaron a cabo una estrategia mayormente defensiva - matizada con entradas punitivas orientadas a castigar a un grupo en particular- como método de apaciguar las fronteras, tanto en los frentes austral (Damianovich 1992) y occidental del Chaco (Vitar 1997) como en los territorios del sur, en donde las posibilidades de una política ofensiva exitosa se reducían al mínimo frente a la enorme amplitud del territorio indígena y los escasos recursos militares (Lázaro Ávila 2002).

Las guerras ofensivas se tradujeron en numerosas entradas y expediciones militares planificadas por los gobernadores hacia el interior de esos extensos territorios, para responder a los malones y saqueos perpetrados por los indios en sus fronteras. De esta mane$\mathrm{ra}$, frecuentemente se echaba mano del

Último y eficaz remedio que es llevar la guerra a fuego y sangre hasta desnaturalizar estos bárbaros de los bosques de que se abrigan como si fueran fieras sin política ni propiedad o costumbre que parezca de hombres, sino de tigres sedientos de la sangre de los cristianos, como lo acreditan las muchas muertes que han ejecutado, y el común sentir de que comen carne humana, y aún son peores que tigres pues matan a sus propios hijos (Urízar y Arespacochaga 24-11-1708).

Este tipo de descripciones tan explícitamente orientadas a señalar que se había obrado en consecuencia, debe interpretarse en relación a la contradicción que suponían las entradas punitivas y de exterminio frente a las Leyes de Indias que prohibían "la guerra ofensiva a indios sino en casos de no poderse conseguir su reducción por los demás medios, o en los casos de no poderse contener en ro- bos y en muertes" (Pastells 1933: 255). Por ello, en la documentación aparecen extensas justificaciones sobre el envío de expediciones y entradas en respuesta a "las invasiones y hostilidades ejecutadas por los indios infieles [...] para darles algún castigo, y recuperar los cautivos", aunque las mismas instrucciones contemplaban "que en primer lugar solicitase la pacificación de los indios requiriéndolos, y procurándolos atraer a la amistad, paz, y buena correspondencia, siguiendo el orden, y método que previenen las leyes de estos reinos" (Salcedo 20-11-1741).

Además de la prohibición mencionada, otros factores -como la fuerte resistencia indígena y una endeble "superioridad militar" que no garantizaba el éxito colonial ${ }^{2}$ - contribuyeron a que se realizaran numerosos esfuerzos por dialogar con los indígenas para establecer paces. A partir de la década de 1730, frente a un recrudecimiento de los ataques indígenas en las fronteras del sur de Santa Fe y el norte de la región pampeana, el proyecto jesuita de fundar reducciones para los indios cobró renovada vigencia. Numerosa correspondencia entre padres de la Compañía de Jesús y funcionarios coloniales dejan constancia de este proyecto de amplio alcance geográfico que buscaba reagrupar y sedentarizar a los grupos nómades en pueblos situados en ambos espacios fronterizos (Pastells 1948). Dentro de este contexto, las incursiones al territorio indígena se orientaron a acordar con determinados caciques la fundación de reducciones. En algunas ocasiones, esto se conseguía pacíficamente a través del diálogo -generalmente acompañado por la entrega de regalos-, como en 1749, cuando el gobernador de Asunción

conduciéndose por el río con ocho embarcaciones que le acompañaron con soldados y otros convidados para el respecto, y pasando después a dicha ciudad de las Corrientes, propuso a los caciques la utilidad de la paz que deseaba con tanta fecundia y energía (sin descaecer un punto el crédito de Vtras. reales armas) y con tan eficaces razones y con el aparato militar, puesto

2 A modo de ejemplo, Dobrizhoffer ([1784] 1969) señala las dificultades de desplegar con éxito acciones militares en determinados espacios chaqueños, en donde los campos inundados enfermaban e inutilizaban a los caballos de los soldados y humedecían la pólvora inhabilitando el uso de las armas de fuego, lo que los posicionaba en clara desventaja frente a las estrategias adaptativas de los indígenas con su entorno natural. 
los soldados en escuadrón que usando su divina majestad de su piedad y misericordia, se ablandaron aquellos corazones de diamantes y de lobos sangrientos, se convirtieron en mansos corderos, aceptaron y asentaron la paz con tan firmes y sólidos fundamentos que se cree permanecerán en ella (González de Guzmán y otros 8-71749).

En términos de permanencia, las reducciones fundadas en el Chaco austral resultaron relativamente exitosas. Por lo menos, los pueblos se mantuvieron en funcionamiento a pesar de que -en muchos de ellos- los grupos no permanecían por largos períodos ${ }^{3}$. En la frontera sur las reducciones intentadas en el siglo XVIII tuvieron una corta vida en el lapso entre 1740 y $1753^{4}$. También allí las “entradas" desde Buenos Aires a tierra de indios "para darles algún castigo, y recuperar los cautivos" eran motivadas y justificadas por "las invasiones y hostilidades ejecutadas por los indios infieles que habitan las dilatadas campañas de esta jurisdicción" (Salcedo 20-11-1741). Para ese momento, ya estaba fundada una de las reducciones en las cercanías de la desembocadura del río Salado (Levaggi 2000), aunque era necesario atraer a otros grupos. Con ese objetivo es enviado, por ejemplo, el teniente de maestre de campo Cristóbal Cabral, quien se entrevistó con un representante, un "tal Juan Gallo fue quien ajustó la paz en nombre de los caciques Bravos, pues lo habían enviado a este fin". El enviado detalla el carácter ceremonial del encuentro:

habiendo llegado a donde estaban dichos indios, se escuadronaron en una fila todos, y de allí fueron saliendo a escaramucearme, y los de las flechas me amagaban al pecho, y pasaban a ponerse en la fila, y los de las lanzas hacían la misma demostra- ción y después que todos ellos se portaron de este modo vinieron los tres caciques a darme la mano, y me dijeron que creían el que iba a darles la paz respecto de haberme ido solo sin tenerles miedo (Cabral 2-11-1741).

Sin embargo, al año siguiente los españoles debieron repetir el intento. De 1742 es el tratado que, con forma de tal, acuerdan "el cacique Bravo, y los demás caciques amigos" y por el cual Bravo pasa a ser "maestre de campo de toda la sierra" y se compromete a dejar que los misioneros prediquen el Evangelio "para que puedan hacerse cristianos todos los que quisieren" y a no impedir que algunos de los suyos que "quisieren avecindarse en la reducción de los Pampas, para hacerse cristianos", lo hicieran (Tratado 1742). Esta era la máxima exigencia que podían tener los funcionarios coloniales con estos grupos y en esta región, donde recién ocho años más tarde lograrían establecer la segunda de tres reducciones.

En la mayoría de los casos, la paz buscada por los hispanocriollos se alcanzaba solo después de enfrentamientos armados y violentos. Las entradas militares, aunque fueran realizadas con fines diplomáticos, se desarrollaban al ritmo de objetivos ambiguos, como aquellas instrucciones redactadas por Pedro de Ceballos - gobernador de Buenos Airespara una incursión al Chaco santafesino, donde se "tendrá presente que el fin principal de esta expedición es obligarlos a que soliciten de veras una paz durable y firme" (Ceballos 6-2-1759). "Obligarlos", habilitaba cualquier medio que garantizara tan conveniente resultado. Así, muchas de las incursiones de mediados del siglo XVIII cobraron la paradójica modalidad de salir a hacer la guerra para fundar la paz: "di cuenta a V.E. haber hecho

3 En este trabajo nos referimos particularmente a las reducciones fundadas durante el siglo XVIII para los grupos nómades abipones y mocovíes del Chaco austral. El primer pueblo fue el de San Javier de indios mocovíes en 1743, seguida en 1748 por la fundación de San Jerónimo de indios abipones, ambas en la jurisdicción de Santa Fe. También para los abipones se fundó, en 1749, la reducción de Concepción en la jurisdicción de Santiago del Estero; en 1750, San Fernando en la jurisdicción de Corrientes y, más tarde, en 1763, la del Santo Rosario o Timbó, en la jurisdicción de Asunción. Poco antes de la expulsión de los jesuitas, en 1765, la ciudad de Santa Fe fundó San Pedro, tercera reducción para los indios mocovíes (Maeder y Gutiérrez 1995).

4 Entre 1740 y 1753 se mantuvo en pie la reducción Nuestra Señora de la Concepción de los Pampas, cerca del río Salado. La segunda reducción, destinada a los puelches o serranos fue fundada en 1746, con el nombre de Nuestra Señora del Pilar, en las inmediaciones de la actual sierra de Tandil y perduró hasta 1751. La tercera de las reducciones de la frontera sur, Nuestra Señora de los Desamparados, fue fundada en 1750 para los indios patagones o tehuelches y abandonada en 1751 (Nacuzzi, Lucaioli y Nesis 2008). 
una entrada contra los indios abipones, conseguido pasar a cuchillo a muchos, rescatar varios cristianos que tenían de lo que resultó pedir paz y religiosos jesuitas para reducirse" (Andonaegui 15-6-1749). También en la región pampeana, relata Levaggi que "después de una expedición punitiva que encabezó el maestre de campo Juan de San Martín" para vengar un ataque indígena a los partidos de Areco y Arrecifes 5 , "los caciques pampas, temerosos de un nuevo castigo, se encaminaron a la ciudad y se presentaron al gobernador" Salcedo con quien "se comprometieron a guardar la paz" (Llevaggi 2000: 104-105). Estos y muchos otros documentos dan cuenta que este tipo de acuerdos era, muy probablemente, el resultado de enfrentamientos armados reiterados o de situaciones de tensión o conflicto muchas veces sangriento, tras los cuales se decía que los indígenas manifestaban "solicitar la paz", "aceptar la paz", "rogar la paz", "tratar las paces”, "parlamentar las paces”.

A través de las armas, y por medio de una interesante estrategia discursiva, el deseo de una conciliación parece trocar de protagonistas. Los relatos elaborados sobre estos encuentros ocultan los intereses coloniales que motivaron las expediciones, transfiriendo a los interlocutores indígenas sus propios objetivos e intereses al recurrir a frases como "vinieron a pedir la paz" o a "pedir reducción" o a "ser abrazados por la Santa Fe Católica", lo que nos lleva a cuestionar la literalidad de los documentos que mencionan a los grupos indígenas pidiendo aquello que más les interesaba conseguir a los misioneros y autoridades coloniales. Pensamos que estas expresiones, puestas en boca de los actores indígenas, reflejaban el interés por parte de los funcionarios coloniales por demostrar y enaltecer frente a sus máximas autoridades un supuesto dominio y control sobre grupos y territorios que, en realidad, se mantenían autónomos respecto del aparato colonial. Una lectura atenta que desmantele la literalidad y contemple la información que se filtra entre líneas nos permite sostener que, incluso en situaciones en las que los intereses de uno y otro lado parecen coincidir y en las que se llega al establecimiento de pueblos de reducción o a la firma de tra- tados, estas expresiones pueden invisibilizar distintos objetivos de uno y otro lado.

Nos detendremos ahora en las formas en que se construyeron estos momentos de "pedir la paz", considerando las acciones, los discursos y los objetos o bienes intercambiados y los sujetos que de uno y otro lado participaban del ceremonial que permitía arribar al acuerdo.

\section{Los rituales de la paz}

Estos pactos se realizaban entre algún cacique que representaba a un grupo indígena y un jesuita, un militar o una autoridad gubernamental. Las paces podían acordarse cuando los funcionarios españoles tomaban la iniciativa y realizaban una expedición particular para este fin o como resultado de incursiones punitivas al territorio indígena en respuesta a malones, asaltos u "ofensas". Algunos acuerdos eran alcanzados en los lugares de encuentro, "tierra adentro" pero, cuando el trato incluía el establecimiento de una reducción, era frecuente que los caciques quedaran comprometidos a acercarse a las ciudades para dialogar con el Gobernador o con el Cabildo. Otras veces, el grupo indígena quedaba obligado a recibir a un misionero en algún paraje dentro de sus territorios. Las variantes y matices de estas situaciones eran múltiples y demandaban largos períodos de negociación, por ejemplo: al no presentarse algunos caciques mocovíes en la fecha acordada en un determinado paraje para fundar una reducción, el propio gobernador de Corrientes salió en su búsque$\mathrm{da}$, logrando solamente promesas de un nuevo encuentro (Patrón 11-12-1752). En el caso de la reducción de San Javier de indios mocovíes, la negociación insumió nueve años entre 1734 y 1743 (Cervera 1907).

Las autoridades españolas destacaban que el hecho de "acordar la paz" con un grupo indígena suponía que habían aceptado la religión católica y se habían transformado en vasallos del rey. Esta nueva condición de vasallos y creyentes no era reconocida por los grupos indígenas y los españoles tampoco podían considerarlo como una situación definitiva, aunque habían cumplido formalmente con las instrucciones reales. El término "vasallo"

5 Bechis (2008: 101-102) realiza un análisis más pormenorizado de estos episodios. 
era utilizado reiteradamente en los relatos en los que se mencionan acuerdos de paz, en la correspondencia de militares y misioneros que hacen referencia a preparativos destinados a esos acuerdos y en Actas de Cabildo donde aparecen discusiones sobre fundaciones de pueblos de reducción. Luego, cuando comenzaron a aparecer escritos con la forma de tratados, el primero de sus artículos hacía referencia a que los integrantes del grupo que pactaba el acuerdo pasaban a ser considerados "vasallos del Rey".

La nueva condición de vasallos no implicaba un cambio real de estatus entre los indígenas ni generaba ajustes sustanciales en las relaciones entre indígenas y españoles. A pesar de que esta formal condición de igualdad frente a la Corona suponía también una "alianza" de indios y españoles ante otros grupos indígenas y otras naciones europeas, en las situaciones cotidianas tanto la igualdad como la alianza se olvidaban rápidamente ante nuevos conflictos que se provocaban desde uno u otro lado. Estos conflictos no nacían solo por el incumplimiento de alguno de los puntos del tratado, la situación de latente tensión y los intereses contrapuestos desataban periódicamente duros enfrentamientos.

En todas estas ocasiones, el término "vasallo" debe entenderse en su acepción de "súbdito de un soberano"7 y no como el de personas que pagan tributo (Nacuzzi 2006). Una de las condiciones que aparece reiteradamente en los escritos que relatan negociaciones para pactar paces o en las instrucciones o textos más formales, es la de que determinados grupos indígenas dejaran sus enfrentamientos en el olvido y se consideraran en adelante como amigos, a la sombra del propio acuerdo con los españoles. Así, el tratado de 1742 que se acordó con el cacique Bravo, presentaba la expectativa de que "se han de olvidar las diferencias pasadas" entre su grupo y el de otro cacique, el pampa Mayupilquia, ya reducido en las cercanías del río Salado. En este caso, hasta el nombre del tratado refleja este importante objetivo: "Capitulaciones de las paces hechas entre los indios Pampas de la Reducción de Nuestra Señora de la Concepción, y los Serranos, Aucas, y Pegüenches, que se han de publicar en presencia del cacique Bravo, y de otros caciques [...]" (Tratado 1742, el destacado es nuestro). En esta y en otras ocasiones, el acuerdo se cerraba con una de las partes a la que se le exigía mantener una buena relación con otros grupos enemistados que estaban ausentes en ese momento. Estas circunstancias dificultaban el cumplimiento de lo que se estaba pactando $y$, por lo tanto, hacían muy vulnerables los objetivos buscados.

Esta intención de las autoridades coloniales de oficiar de mediadoras entre dos grupos se encuentra en numerosos papeles que relatan esfuerzos por mantener las paces ya pactadas. Por ejemplo, en 1748 catorce caciques abipones "ofrecieron su amistad a los españoles" y cada uno de ellos tomó a su cargo la defensa de sus ciudades (Asunción, Corrientes, Santiago del Estero, Santa Fe y Córdoba), y luego se radicaron en las tres reducciones fundadas en el Chaco austral (San Jerónimo, Concepción y San Fernando). Pocos meses después, uno de los caciques atacó Asunción rompiendo lo pactado, despertando antiguos enfrentamientos con los otros caciques y poniendo en peligro la continuidad de las reducciones. En este escenario donde había personajes indígenas que guardaban "fielmente los pactos" y otros que no, los funcionarios españoles, en pos de mantener los mencionados acuerdos, actuaron como pacificadores y mediadores entre los grupos abipones de diferentes caciques enemistados (Dobrizhoffer [1784] 1969: 129).

Los intentos por generar armonía entre diferentes grupos indígenas, seguramente tenían relación con el objetivo de mantener los espacios fronterizos en calma. Otra intención explícita en los acuerdos de paz era asignarles un territorio específico -ya fuera una reducción o un paraje determinado- a los caciques que se involucraban en el acuerdo para lograr un mejor control de los movimientos de estos grupos nómades. Estos esfuerzos nunca fueron exitosos. En los momentos de acordar la

6 Por ejemplo: Capitulaciones entre el gobernador de Tucumán Esteban de Urízar y Arespacochaga y los malbaláes, agosto de 1710 (citado por Levaggi 2000: 52-53) y “Capitulaciones de las paces hechas entre los indios Pampas ...” en 1742 (citado por Levaggi 2000: 107-108).

7 En algunos documentos, incluso aparece utilizado para referirse a los seguidores de los principales caciques (Martínez Fontes 25-10-1762). 
paz, los españoles contaban con ciertos recursos -armas, uniformes, entregas de regalos y ganado- que resultaban convincentes como para comprometer a los grupos a consentir los términos de cada acuerdo; sin embargo, las obligaciones que asumían los grupos indígenas eran rápidamente olvidadas. Los caciques no tenían alicientes para cumplirlas y los españoles no poseían el suficiente control como para hacerlas cumplir.

\section{El valor de lo inmediato}

Ante este panorama, cabe preguntarse por qué unos y otros seguían interesados en establecer acuerdos. Si bien los españoles debían cumplir las políticas de colonización y trato hacia los indios, del lado indígena no había obligaciones diplomáticas preestablecidas. Si ponemos la mirada en las rutinas seguidas en los momentos de establecer los pactos, se evidencia la importancia de los bienes que circulaban entre ambas partes y su influencia en la obtención de buenos resultados. La entrega de vestimentas, objetos suntuarios, baratijas y ganado que acompañaba las conversaciones de paz, posiblemente resultaban un aliciente para que los grupos indígenas aceptaran los términos del acuerdo que se les proponía. Coincidimos con Cervera (1907: 502) en que la "paz, no era muchas veces, más que un descanso adquirido a fuerza de regalos y compromisos que se ofrecían a los indios, los que rompían la paz, cuando no estaban satisfechos". Por ejemplo, luego de que fracasaron los insistentes intentos armados llevados adelante por el gobernador del Tucumán, Ángel de Paredo, durante la década de 1670, cambiando de estrategia dicho funcionario "Había logrado por fin con regalitos y chucherías que un grupo de aquellos, depuesta su enemistad, se establecieran en los lugares vecinos a la ciudad de Esteco y se sometieran a la misión" (Dobrizhoffer [1784] 1969: 116).

Si bien las menciones sobre entregas de "regalitos y chucherías" para establecer diálogos son muy comunes en los documentos de fechas tempranas, hacia mediados del siglo XVIII -en un escenario más complejo con relaciones interétnicas más intensas y que ya contaba con una larga historia de contactos, enfrentamientos y alianzas - las negociaciones de paz y los compromisos de reducción involucraban la entrega de otro tipo de bienes, de mayor valor, incluso para los sectores coloniales. En numerosas ocasiones los gobernadores debían acudir a la limosna pública o a la entrega de donativos para conducir grandes manadas de ganado vacuno destinadas a atraer a los grupos indígenas al diálogo diplomático (Lucaioli 2006).

Muchas veces, estos donativos incentivaban a que los caciques brindaran valiosas informaciones sobre otros grupos indígenas. La obtención de información era una excelente compensación para los españoles que casi siempre estaban en territorios mal conocidos y poco sabían de los grupos que lo habitaban, por lo cual tales comunicaciones solían formar parte -no necesariamente de manera explícita- de las contraprestaciones indígenas. Por ejemplo, durante un acuerdo logrado con los grupos abipones y mocovíes confederados que se comprometieron a reducirse, "Valiéndose el comandante de la confusión en que los veía, logró la ocasión de informarse de todas las distancias, que median desde La Cangayé a las ciudades de Corrientes, Santa Fe, Córdoba y Santiago" (Campero 7-3-1765).

Por su inmediatez, las acciones que acompañaban el ceremonial del acuerdo aseguraban la obtención de ciertos beneficios como los intercambios de información por bienes. Los indiscutibles frutos del encuentro se reducían a los resultados concretos que pudieran obtenerse en el trascurso de la negociación, el resto de las obligaciones que se programaban a futuro resultaban, casi siempre, promesas que no se cumplían. Los documentos ofrecen numerosas referencias sobre la programación de fechas futuras para continuar con las negociaciones o dar comienzo a la fundación de reducciones que, en una gran mayoría, no llegaban a materializarse. Con esto no estamos sugiriendo que los únicos beneficios de estos encuentros quedaban acotados a las transacciones inmediatas, ni que el acuerdo de compromisos desplazados en el tiempo carecieran de valor, incluso cuando no se cumplieran. Creemos que, como en toda relación, el establecimiento de estos diálogos creaba importantes antecedentes que influían en los mecanismos de las relaciones interétnicas $y$, según fuera el caso, acercaba o distanciaba a los grupos en cuestión.

El intercambio de información también formaba parte de una serie de compromisos 
futuros a los que ambas partes se obligaban, junto con la defensa de las fronteras, ciudades y estancias, la catequización, la entrega de ganados y alimentos.

\section{Las promesas para el futuro}

Entre las obligaciones que una y otra parte asumían en cada acuerdo, se destacan las que buscaban evitar que se repitieran conflictos en las fronteras. Los grupos indígenas se comprometían a reducirse bajo la custodia de un misionero y/o a "guardar la paz" y defender las ciudades del ataque de otros grupos. Los hispanocriollos se responsabilizaban de designar un misionero y de proveer los recursos materiales necesarios para establecer y mantener la reducción. Por otro lado, ambas partes obtenían ciertos beneficios. Es difícil describir cuáles acciones eran obligaciones y cuáles eran beneficios, puesto que lo que se le exigía a una de las partes podía ser ventajoso para la otra.

En tanto estos acuerdos tenían como principal finalidad crear relaciones de amistad entre algunos caciques y determinadas ciudades, esta intención quedaba manifestada reiteradamente como el primer objetivo de cada pacto. Se esperaba que los grupos indígenas amigos cesaran los ataques a los establecimientos coloniales. Antonio de Vera Mujica, gobernador de Santa Fe, explicitó este punto a los abipones que acordarían las paces y reducción con la ciudad de Corrientes, señalándoles que "después de haber hecho la paz con el Gobernador de la provincia, no les era permitido inquietar una ciudad de su gobernación" (Charlevoix 1916: 137).

Cuando recién estaban comenzando los intentos de fundar reducciones en la frontera sur, las incursiones militares buscaban sellar algunos compromisos, "el dicho don Felipe queda con quince toldos de indios que tiene a su cargo en esta sierra del Cairú, para la defensa y seguro de Buenos Aires" (Cabral 2-111741). Sin embargo, la obligación indígena de no atacar a las ciudades y mantener la paz en las fronteras no siempre se cumplía: "Aunque todo el pueblo de los abipones guardó fielmente los pactos, poco meses después unos pocos, olvidando la fe dada, reanudaron las hostilidades" (Dobrizhoffer [1784] 1969: 130).
Se esperaba que los grupos se redujeran en pueblos de indios en las inmediaciones de la frontera. Hacia mediados del siglo XVIII, el hecho de que aceptasen reducirse parecía brindar mayores garantías de que se mantendrían las paces. La distancia y características del terreno en donde se emplazaría la reducción de la ciudad que la patrocinaba era un punto de mucha importancia en función de sus potencialidades defensivas, ya sea para que los grupos indígenas pudieran proteger las fronteras como para que los funcionarios hispanocriollos tuvieran cierto control sobre estos pueblos. Aun cuando no se les ofrecía o exigía reducción, sí se les pedía que se instalaran en algún paraje: "El cacique Bravo, y los demás caciques amigos pondrán sus tolderías en el Tandil y Cayrú" (Tratado 1742). Ambas alternativas, la reducción o la instalación en un determinado sitio, buscaban reducir los movimientos por el territorio, lo cual era la principal dificultad para controlar a los grupos nómades.

Otra obligación de los grupos indígenas que resultaba beneficiosa para los españoles era la de contener los ataques de los enemigos de la Corona, ya fueran indígenas o potencias extranjeras. Este posible peligro era explicitado tanto en la región del Chaco como en la frontera sur. En un tratado que se acordó con los caciques de las sierras de la Ventana se manifiesta que uno de ellos, Calpisqui o Callfilqui, sería nombrado "cacique principal de todas la pampas" y esto lo comprometía a "impedir el que, no solamente los caciques de su alianza, sino otros cualesquiera, entren a dichas pampas a potrear sin su licencia". El convenio incluía dar aviso sobre la presencia de "otros güincas, que por mar o tierra sean encontrados por aquellos parajes" (Tratado 1790).

En el marco de estas nuevas relaciones de amistad, los grupos indígenas quedaban habilitados para visitar las ciudades y/o establecerse en ellas:

La ciudad de Santa Fe fue la primera en concertar la paz con abipones y mocobíes. Algunos grupos de ellos, iniciada la paz, se establecieron con sus familias en campos cercanos a la ciudad, y vivían comprando lo que deseaban y vendiendo en la plaza pública lo que habían robado a otros pueblos enemigos de los españoles (Dobrizhoffer [1784] 1969: 109). 
En la frontera sur, por las paces que en el año 1742 se habían acordado "con todos los indios Pampas", entre ellos Bravo y Calelian, se rescataban cautivos que estos indios llevaban a la ciudad y "se les ha tratado como amigos, admitiéndoles el comercio de sus ponchos siempre que han venido a ejecutarlo" (Marcoleta 1745).

Para los indígenas, el mayor atractivo económico era el acceso a ganados y esto se veía reflejado en los acuerdos. En el caso de la frontera sur, se les "designaba" un paraje "para potrear" y el control de esta actividad sobre otros grupos (Nacuzzi 2006), aunque se trataba de una mera formalidad ya que gozaban de una amplia libertad en sus movimientos y no tenían motivos para limitarse a obtener ganado solo en los espacios predeterminados. Para los grupos del Chaco, la fundación de reducciones iban acompañadas de entregas de ganado y de promesas de continuar abasteciendo la subsistencia. Sin embargo, los donativos y entregas posteriores no siempre se cumplían en tiempo y forma: los plazos se dilataban, se entregaban pocos animales o animales viejos (Lucaioli y Nesis 2007).

Las relaciones amistosas entre indígenas y españoles promovían cierto intercambio de favores. Por ejemplo, los caciques reducidos del Chaco ayudaban a recuperar ganados robados por otros grupos o colaboraban con los jesuitas en diversas tareas y eran recompensados con regalos: "El mismo gobernador real de Tucumán, [...] le dio insistentemente las gracias y remuneró la tarea cumplida de transportar las cosas de la misión desierta, con un paño rojo que bastaría para vestir a cualquier español noble" (Dobrizhoffer [1784] 1969: 144). A menudo estas prestaciones incluían la promesa de ayuda defensiva desde ambas partes. El cacique Bravo oficiaría de "maestre de campo de toda la sierra" y no debería dejar pasar a ningún indio hacia Buenos Aires sin permiso del Gobernador (Tratado 1742). En el Chaco, a cambio de que las reducciones frenaran los ataques de otros grupos indígenas a las ciudades, los españoles prometían apoyarlas militarmente en el caso de que esos mismos grupos volvieran sus ataques hacia ellas. Estos compromisos no se cumplían, los españoles ponían excusas y demoraban la ayuda. En un conflicto entre mocovíes y abipones, estos le solicitaron al teniente de gobernador de Corrientes que interviniera y él alegó que estaba envuelto en otra expedición [...]; pero en cuanto volviera a su casa una vez terminada la presente guerra, se dirigiría contra los mocobíes con algunos cientos de sus jinetes. Dijo esto y volvió a la ciudad alegando algún asunto, no sé cuál, no quedando de su venida ningún fruto, más que una mayor irritación de los indios (Dobrizhoffer [1784] 1969: 262).

Según reconstruye Levaggi (2000: 302), desde el lado indígena tampoco se honraban los acuerdos de no agresión. En 1739, ante el pedido de algunos caciques pampas para que se "les permitiese habitar entre los españoles", el gobernador de Buenos Aires, Miguel de Salcedo, les "respondió que solo los protegería si se juntaban en pueblo y admitían misioneros". Aceptada esa oferta por parte de los indios, se fundó en mayo de 1740 Nuestra Señora de la Purísima Concepción. Sin embargo, la ciudad fue acosada nuevamente por malones y el gobernador debió enviar una nueva expedición - la de Cristóbal Cabral, que tuvo lugar entre el 8 y el 27 de octubre de 1741para volver a pactar las paces. En esa ocasión, Cabral le envió al cacique Bravo yerba, tabaco, cuchillos y 80 cabezas de ganado en calidad de obsequio y para que pudiese rescatar cautivos que estaban "tierra adentro en poder de los Aucas" (Cabral 2-11-1741).

En todas las negociaciones para la firma de tratados de paz o el establecimiento de alianzas entre grupos indígenas y funcionarios coloniales, encontramos que, de una u otra manera, se involucraba la entrega de cautivos, ya fueran indígenas o hispanocriollos. Teniendo en cuenta las distintas estrategias implementadas para sellar los acuerdos, creemos que esta recurrencia merece una reflexión pormenorizada que permita identificar los roles desempeñados por los cautivos y los convenios para garantizar su liberación y las distintas formas en que el intercambio se llevaba a cabo.

\section{El intercambio de cautivos}

Releyendo desde esta perspectiva los documentos analizados hemos podido identificar distintas rutinas asociadas a la entrega de cautivos en el contexto de las firmas de paces y en diferentes momentos de las nego- 
ciaciones. La circulación de personas privadas de su libertad, entendida como relaciones de intercambio entre los sectores coloniales e indígenas, era frecuente durante los períodos de paz, seguramente fortalecía las relaciones de amistad y posibilitaba a ambos grupos acceder a ciertos beneficios e influenciar sobre determinado tipo de acciones. Así, por ejemplo, encontramos que con motivo de la tregua concedida por el cacique abipón Ychoalay a Santa Fe, el gobernador de dicha provincia anunció un canje con aquel para intimarlo a mediar en los conflictos fronterizos de otros grupos abipones con la ciudad de Corrientes, "entregándole ocho prisioneros de su nación, y que este envió doce esclavas o cautivas" (Patrón 29-12-1749).

Este tipo de intercambio era más frecuente durante el momento mismo del establecimiento de los pactos. El mencionado gobernador de Buenos Aires, Miguel de Salcedo, informa a sus superiores que su orden de "atraer a la paz" a algunos grupos indígenas, se había conseguido "con bastante felicidad", "obligándose los indios a restituir las cautivas" (Salcedo 20-11-1741). Algunos acuerdos se cerraban con un canje ceremonial de cautivos, como demostración de buena fe por ambas partes y de haber asumido los compromisos pactados. Luego de que varios caciques abipones en asamblea acordaran sellar las paces con las distintas ciudades coloniales,

se agregó la cláusula de que se concedería a los abipones y mocobíes cautivos de los españoles, amplia libertad de volver con los suyos. Para que el precio de la libertad fuera íntegro, también los cristianos cautivos de los abipones debían ir donde quisieran (Dobrizhoffer [1784] 1969: 129).

En los acuerdos en donde probablemente no quedaba constancia escrita ni los españoles podían contar con el recurso de la firma como garantía de lo pactado, creemos que el acto de entrega mutua de cautivos podría haber gozado de cierto valor simbólico que ponía a las partes en condiciones de igualdad en donde una y otra tenían los mismos derechos - de recuperar a su gente- y las mismas obligaciones - de liberar a sus cautivos.

En algunas ocasiones en que los pactos se celebraban en el interior del Chaco, solía ocurrir que solo los grupos indígenas entregaban a sus cautivos luego de los acuerdos. Con motivo de una tregua alcanzada entre el gobernador de Asunción y algunos caciques abipones y mocovíes en las inmediaciones de la ciudad de Corrientes, estos grupos aceptaron la paz "y en confirmación de su amistad, restituyeron tres cautivas de las que habían apresado, quedando de restituir las demás, que no lo hicieron luego por estar distantes en otras tolderías" (González Guzmán y otros 8-7-1749). Este ejemplo nos permite observar que en ciertas ocasiones la entrega de cautivos como garantía de lo pactado constituía un derecho de una de las partes -en este caso del sector colonial- pero que, a su vez, se trataba de una prestación lo suficientemente flexible como para cumplirla a medias. Volvemos aquí sobre aquello que hemos llamado el valor de lo inmediato frente a las dilaciones que permitían desdibujar los derechos y obligaciones acordadas, señalando que los beneficios concretos de los acuerdos estaban íntimamente ligados al momento mismo de la transacción.

En otras oportunidades, el intercambio de personas formaba parte del conjunto de prestaciones y contraprestaciones definidas y del acervo de los intercambios materiales, junto con las entregas de ganados, objetos suntuarios o bienes de origen europeo. Incluso en el episodio que hemos comentado del tratado de paz entre varios caciques abipones y varias ciudades coloniales en donde se acordó la entrega mutua de cautivos, hallamos que mientras los españoles dejaron en libertad a los indígenas prisioneros, los suyos debieron ser "rescatados por medio de frenos, espadas, sombreros, vestidos de lana o bolas de vidrio" (Dobrizhoffer [1784] 1969: 129). Así, la obligación de devolver a los cautivos por parte de los grupos indígenas podía utilizarse estratégica y convenientemente para conseguir mayores beneficios materiales o, como señalamos en el ejemplo anterior, para mantener parte de sus recursos.

Estas estrategias de cumplir a medias o sacar mayores provechos de las nuevas relaciones, podían combinarse y adquirir en la práctica numerosos matices. Por ejemplo, en la región pampeana, en 1745, habiendo pasado tres años desde el acuerdo que se había alcanzado con Bravo (Tratado 1742), en un Memorial que relata diversas hostilidades y con- 
flictos con indios de la frontera sur, sobre todo con los caciques Bravo y Calelian, se afirma en referencia al primero que no había cumplido lo acordado en el tratado: ni había ayudado a defender a la ciudad de otros grupos indígenas ni había devuelto cautivos, cuando los españoles habían devuelto hasta indios "acristianados" (Marcoleta 1745).

En el complejo juego de derechos y obligaciones delineado por las relaciones diplomáticas, los grupos indígenas también utilizaron la estrategia de solicitar la paz y reducción como medio para rescatar a otros indígenas que habían sido llevados a las ciudades para prestar servicio personal en las casas de los españoles (Furlong 1938). Un ejemplo elocuente acerca de la plasticidad de este recurso lo hallamos en las negociaciones que dieron lugar a la fundación de la reducción de Concepción de abipones en la jurisdicción de Santiago del Estero, en 1749. Dobrizhoffer señala a Cristóbal Almaraz, un español criado desde pequeño entre los abipones, como el principal representante del lado indígena en las conversaciones de paz. Almaraz, de reconocido prestigio entre los abipones por sus demostraciones bélicas, se había casado con una mujer noble de ese grupo que, luego de haberle dado varios hijos, había sido llevada por Barreda - gobernador de Santiago del Esterojunto a otras mujeres para prestar servicios en la ciudad. Para recuperar a su esposa,

\begin{abstract}
Almaraz con su cacique Alaikin trató con todo empeño de que se le pidiera a $\mathrm{Ba}$ rreda el pueblo que estaba por fundarse para sus compatriotas. Afirmaba que este sería el medio más seguro y único con que todos los cautivos recuperarían su libertad (Dobrizhoffer [1784] 1969: 193).
\end{abstract}

Finalmente, a cambio de la liberación de los cautivos indígenas, los grupos abipones acordaron asentarse en un pueblo de reducción y obedecer a los padres jesuitas. Por el contrario, cuando el deseo de recuperar personas corría por parte del sector colonial, las contraprestaciones solían reducirse únicamente al precio del rescate. En estas ocasiones se realizaban expediciones al interior del territorio indígena para negociar directamente con los caciques la liberación de los individuos que permanecían entre ellos. Estos acuerdos generalmente no definían obligaciones a futuro y la transacción contemplaba la entrega de bienes a cambio de los cautivos hispanocriollos. Sea cual fuera el motivo, los cautivos jugaban un papel potencialmente importante en la definición de alianzas y, en torno a ellos, ambos grupos desplegaron variadas estrategias orientadas a conseguir acuerdos ventajosos y obtener mayores ganancias económicas y políticas.

\section{Consideraciones finales}

Dentro del contexto general delineado por las reformas borbónicas en las colonias americanas, una de las principales preocupaciones por parte de los representantes de la Corona era posicionarse ventajosamente frente a otras potencias europeas. Para ello, era fundamental pacificar las fronteras, lo que les permitiría mantener ocupados los espacios ya colonizados que los enfrentamientos indígenas hacían peligrar (como la frontera sur del Chaco) y, por sobre todo, posibilitaría controlar y conocer el territorio (como en la Pampa y el norte de la Patagonia), ordenar a los grupos indígenas y subordinarlos al rey y a la religión. Para alcanzar estos objetivos, a las políticas ofensivas y defensivas implementadas hasta entonces se sumó una nueva modalidad, la búsqueda de diálogo y negociaciones con los grupos indígenas.

Las acciones diplomáticas orientadas a la conquista del territorio chaqueño y de la región pampeano-patagónica y a la colonización de los grupos nómades que lo habitaban, en la práctica adoptaron dinámicas originales y se redefinieron sus formas en función de las coyunturas regionales y los intereses inmediatos de ambas partes. Los pactos de paz propuestos por los hispanocriollos y, más aún, la fundación de reducciones fueron formas de interacción de origen colonial que los grupos indígenas supieron manipular y redefinir para lograr sus propios intereses. El establecimiento de acuerdos durante el siglo XVIII, de ninguna manera debe interpretarse como una relación de subordinación de los grupos indígenas respecto de la Corona, ni tampoco como el surgimiento de fuertes alianzas o duraderas relaciones de amistad. Si bien en muchas ocasiones las negociaciones diplomáticas lograron disminuir los conflictos, este resultado se materializó bajo la forma de treguas de corto plazo, inestable y con una flexible redefinición de los puntos acordados. 
En ciertas ocasiones la estrategia de pedir la paz fue utilizada por los grupos nómades que se hallaban cercados por tropas españolas paradójicamente para conseguir una oportunidad de evadir un inminente enfrentamiento armado. Sabiendo qué se esperaba de ellos, los grupos indígenas apelaban a ese conocimiento para generar situaciones favorables. Por ejemplo, manifestar la intención de reducirse se convertía en una buena vía para demorar posibles acciones armadas y conseguir que se les permitiera internarse aún más en el territorio con la excusa de sumar a otros caciques al acuerdo, creando las condiciones necesarias para burlar a los españoles y los principios del supuesto acuerdo (Gullón Abao 1993). Esta estrategia nos habla de un profundo conocimiento por parte de los grupos indígenas de las acciones políticas coloniales, de la manera en que debían proceder para neutralizarlas y de la capacidad de resignificar estas prácticas echando mano de otras variables ventajosas, como conseguir pacíficamente internarse en un territorio que solo ellos conocían y en donde sabían que sería muy difícil que pudieran controlarlos. También hemos señalado cómo en hechos tan concretos como la entrega de cautivos, los grupos indígenas hallaron la manera de redefinir estos intercambios para conseguir mayores beneficios, como la adquisición de determinados bienes a cambio de personas.

En las ocasiones donde sí llegaron a materializarse parte de los acuerdos -ya fuera el establecimiento de relaciones de amistad entre caciques y gobernadores, la fundación reducciones en los espacios fronterizos o el intercambio de cautivos - los grupos indígenas hallaron la forma de encauzar sus intereses redefiniendo los términos de la interacción y sacando su propio provecho de la situación. Las relaciones de amistad entre caciques y funcionarios coloniales podían convertirse en una excelente vía para conseguir bienes de prestigio o cabezas de ganado que les permitiera a los líderes indígenas incorporarlos en sus propias esferas políticas para aumentar su renombre y fortalecer su autoridad (Nacuzzi 1998, Lucaioli 2008). Asimismo, las reducciones fueron refuncionalizadas por los grupos indígenas, quienes hicieron un uso estratégico de estos espacios combinando sus propias formas de vida política y económica con las ventajas que suponían estos nuevos enclaves: las entregas de ganados y alimentos por parte de los curas, la presencia de corrales para el resguardo de animales orientado al intercambio y un espacio seguro en donde podían permanecer los ancianos, mujeres y niños mientras los hombres realizaban excursiones de caza o guerra (Lucaioli y Nesis 2007) y sitios de paso para obtener información sobre los movimientos de las tropas coloniales (Marcoleta 1745).

Lejos de alcanzar los objetivos propuestos por los funcionarios coloniales de sedentarizar a los grupos nómades y someterlos como vasallos del Rey y de la Iglesia Católica, los pueblos de reducción brindaron numerosas herramientas que los indígenas supieron aprovechar para mantener un notable grado de autonomía hasta bien entrado el siglo XIX. A mediados del siglo XVIII, tanto en el Chaco como en la Pampa, la formación de pueblos de reducción a cargo de jesuitas constituía una de las políticas que buscaba controlar a los grupos nómades. Sin embargo, las características geopolíticas de cada uno de estos espacios condujo a que los funcionarios de la Corona adaptaran sus pretensiones de convertir, controlar y fijar a los indígenas, implementando estrategias alternativas y coyunturales que muchas veces se decidían en cada situación frente a los actores involucrados. En la frontera sur, la fundación de reducciones no prosperó; las establecidas en la década de 1740 fueron levantadas por las autoridades de Buenos Aires y los tratados de paz que se acordaron en adelante solo se orientaban a impedir que los indígenas se apropiaran de ganado y a fomentar la devolución de cautivos (Nacuzzi 2006). En el Chaco, tras la expulsión de los jesuitas, las reducciones pasaron a ser administradas por la Orden franciscana y esto implicó numerosos cambios en cuanto a la entrega de ganados, los intentos por regular los movimientos de los grupos y el uso de estos espacios por parte de los indígenas. 


\section{Bibliografía citada}

BECHIS, M. (2008), Piezas de etnohistoria del sur sudamericano. Madrid, CSIC.

BRIONES, C. y CARRASCO, M (2000), Pacta Sunt Servanda. Capitulaciones, convenios y tratados con indígenas en Pampa y Patagonia (Argentina 1742-1878), Copenhague, Vinciguerra/IWGIA.

CERVERA, M. (1907), Historia de la ciudad y provincia de Santa Fe 1573-1853. Santa Fe, R. Ibáñez.

CHARLEVOIX, P. [1779] (1916), Historia del Paraguay. Tomo VI. En: Los Jesuitas en el Río de la Plata, 1586-1830 I. Madrid, Librería General de Victoriano Suárez.

CRIVELLI MONTERO, E. (1991), Malones: ¿Saqueo o estrategia? El objetivo de las invasiones de 1780 y 1783 a la frontera de Buenos Aires. Todo es Historia 283: 6-32.

DAMIANOVICH, A. (1992), Los inicios de la guerra ofensiva contra mocovíes y abipones: las campañas santafesinas de 1728 y 1729 . Revista de la Junta Provincial de Estudios Históricos de Santa Fe LVIII: 153-167. Santa Fe.

DOBRIZHOFFER, M. [1784] (1969), Historia de los abipones. Vol. III. Resistencia, Universidad Nacional del Nordeste.

FURLONG, G. (1938), Entre los abipones del Chaco. Buenos Aires, Talleres Gráficos San Pablo.

GULLÓN ABAO, A. (1993), La frontera del Chaco en la gobernación del Tucumán, 1750-1810. Cádiz, Servicio de Publicaciones Universidad de Cádiz.

LAZARO ÁVILA, C. (1998), Parlamentos de paz en la Araucanía y las Pampas: una visión comparativa (1604-1820), Memoria Americana 7: 29-60.

(1999), Conquista, control y convicción: el papel de los parlamentos indígenas en México, el Chaco y Norteamérica. Revista de Indias LIX (217): 645-673.

(2002), El parlamentarismo fronterizo en la Araucanía y las pampas. En: Boccara, G. (ed.), Colonización, resistencia y mestizaje en la Américas (siglos XVI-XX):
201-237. Quito-Lima, Ed. Editorial Abya Yala - IFEA.

LEVAGGI, A. (2000), Paz en la frontera. Historia de las relaciones diplomáticas con las comunidades indígenas en la Argentina (Siglos XVI-XIX), Buenos Aires, Universidad del Museo Social Argentino.

LUCAIOLI, C. (2006), Desenredando sujetos, objetos e intereses: una primera aproximación al estudio de las relaciones de intercambio en el Chaco santafesino (siglo XVIII), Actas XX Jornadas de Historia Económica. Universidad Nacional de Mar del Plata. Mar del Plata, Asociación Argentina de Historia Económica. Publicación en CD.

(2009), Alianzas y estrategias de los líderes indígenas abipones en un espacio fronterizo colonial (Chaco, siglo XVIII), Revista Española de Antropología Americana 39 (1): 77-96.

LUCAIOLI, C. y NESIS, F. (2007), Apropiación, distribución e intercambio: el ganado vacuno en el marco de las reducciones de abipones y mocoví (1743-1767), Andes 18: 129-152. Salta.

MAEDER, E. J. A. y GUTIÉRREZ, R. (1995), Atlas histórico del nordeste argentino. Resistencia, Instituto de Investigaciones

Geohistóricas/CONICET/FUNDANORD/Universidad Nacional del Nordeste.

NACUZZI, L. (1998), Identidades impuestas. Tehuelches, aucas y pampas en el norte de la Patagonia. Buenos Aires, Sociedad Argentina de Antropología.

(2006), Tratados de paz, grupos étnicos y territorios en disputa a fines del siglo XVIII. Investigaciones sociales 17: 435456. Lima.

NACUZZI, L.R., LUCAIOLI, C. P. y NESIS, F. S. (2008), Pueblos nómades en un estado colonial. Buenos Aires, Antropofagia.

NESIS, F. S. (2007), Paces y asaltos: estrategias políticas de los grupos mocoví hacia fines del siglo XVIII. Ponencia presentada al Simposio "El liderazgo indígena en los espacios fronterizos americanos (siglos XVIII-XIX)". Buenos Aires, MS. 
PASTELLS, P. (1933), Historia de la Compañía de Jesús en la Provincia del Paraguay. Según documentos originales del Archivo General de Indias V. Madrid, Librería General de Victoriano Suárez.

(1948), Historia de la Compañía de Jesús en la Provincia del Paraguay. Según documentos originales del Archivo General de Indias VII, 1731-1751. Madrid, Librería General de Victoriano Suárez.

ROULET, F. (2004), Con la pluma y la palabra. El lado oscuro de las negociaciones de paz entre españoles e indígenas. Revista de Indias LXIV (231): 313-347.

TAMAGNINI, M y PÉREZ ZAVALA G. (2002), El debilitamiento de los ranqueles: el tratado de paz de 1872 y los conflictos intraétnicos. En Nacuzzi, L. (comp.); Funcionarios, diplomáticos, guerreros. Miradas hacia el otro en las fronteras de Pampa y Patagonia (siglos XVIII y $X I X): 119-157$. Buenos Aires, Sociedad Argentina de Antropología.

\section{Documentos citados:}

ANDONAEGUI, J. [15-6-1749], Carta del Gobernador José de Andonaegui al Marqués de la Ensenada. Buenos Aires, 15 de junio de 1749. AGI, Buenos Aires 304.

CABRAL, C. [02-11-1741], Copia de carta de Cristóbal Cabral al Gobernador Miguel de Salcedo. Sierra del Cairú, 2 de noviembre de 1741. AGI, Buenos Aires 302.

CAMPERO, J. M. [07-3-1765], Carta del Gobernador Juan Manuel Campero a (?). Tucumán, 7 de marzo de 1765. AGI, Buenos Aires 18.

CEBALLOS, P. [6-2-1759], Copia de instrucción escrita por Pedro de Ceballos a (?). San Borja, 6 de febrero de 1759. AGI, Buenos Aires 18.

GONZÁLEZ DE GUZMÁN, A. y otros [8-7-1749], Carta de Antonio González de Guzmán, Antonio Caballero de Añasco, José Canales y Cabrera y
Andrés Felipe Quiñones a (?). Asunción, 8 de julio de 1749. AGI, Buenos Aires 48.

MARCOLETA, D. [1745], Memorial impreso de Domingo Marcoleta acompañado de una información como también de los Acuerdos sobre la hostilidad del indio Calchano o Caleliano. Sin lugar ni fecha. AGI, Charcas 317.

MARTÍNEZ FONTES, J. [25-10-1762], Carta de Joseph Martínez Fontes al padre Provincial Nicolás Contucci. Asunción del Paraguay, 25 de octubre de 1762. ANA vol. 133, $\mathrm{N}^{\circ} 9$.

PATRÓN, N. [29-12-1749], Carta del Gobernador Nicolás Patrón a (?). Buenos Aires, 29 de diciembre de 1749. AGN IX 3-3-6.

[11-12-1752], Carta del Gobernador Nicolás Patrón a (?). Corrientes, 11 de diciembre de 1752. AGN IX 3-3-6.

SALCEDO, M. [20-11-1741], Carta del Gobernador Don Miguel de Salcedo a José de la Quintana. Buenos Aires, 20 de noviembre de 1741. AGI, Buenos Aires 302.

TRATADO 1742 [1742], "Capitulaciones de las paces hechas entre los indios Pampas de la Reducción de Ntra. Sra. de la Concepción, y los Serranos, Aucas, y Pegüenches, que se han de publicar en presencia del cacique Brabo, y de otros caciques, y también en la dicha Reducción por orden del Sr. D. Miguel de Salcedo, gobernador, y capitán general de la provincia del Río de la Plata”. En Levaggi 2000: 107. 108.

TRATADO 1790 [1790], “Tratados que deberá observar con este Superior Gobierno el cacique Callfilqui ...”. En Levaggi 2000: 135 a 137.

Urízar y Arespacochaga, Esteban [24-11-1708], Carta del Gobernador Esteban de Urízar y Arespacochaga a (?). Salta, 24 de noviembre de 1708. AGI, Charcas 210. 